June 2002

\title{
TAXICAB REGULATION IN JAPAN
}

\author{
David Flath*
}

\begin{abstract}
This paper proposes a model of a cruising taxicab industry under laissez fiire pricing and free entry, and compares it with alternative regimes including collusive fare setting, collusive restrictions on entry, or both. In the model, under laissez faire, prices are determined by Nash bargaining with complete information and lie above marginal costs. Under laissez faire pricing and free entry the number of vacant cabs need not be efficient and could be either higher than optimal or less depending upon the relative bargaining power of individual cabs and potential customers. Under collusive control of entry, the number of vacant cabs will be set at the efficient level given the prices, which if set collusively will be above the laissez faire prices. These findings shed new light on the political success of cartelizing regulation of the cruising taxicab industry such as that observed in Japan. JEL classifications D40, L43, L51 and L92.
\end{abstract}

*North Carolina State University and Kyoto Institute of Economic Research (Kyoto University).

David Flath

Kyoto Institute of Economic Research, Kyoto University

Yoshida-Honmachi, Sakyo-ku, Kyoto 606-8501

JAPAN.

Tel. +81-75-753-7137

Fax. +81-75-753-7198

E-mail.david_flath@ncsu.edu 


\section{TAXICAB REGULATION IN JAPAN}

\section{Introduction.}

Many economists over the years have sought to understand the rationale and economic effects of taxicab regulation. Nevertheless, a convincing model of the pricing and supply of cruising taxi services in the absence of regulation remains elusive. It might seem very natural to model the laissez faire situation as one in which taxis each precommit to a posted price and fully informed demanders then choose to wait for a cruising cab or not. But as Stiglitz (1989) has argued, a pure-strategy Nash solution does not exist under this regime. In particular, if all cabs but one set the same price, then the one always enlarges its own revenue and profit by slightly raising its price above the others. The unlikelihood that any one demander will hail this cab is small and so its price has a negligible effect on the market demand. Yet the one whose misfortune it is to hail that cab will not wave it off because this would mean waiting for the next idle cab and waiting is a bad. All cabs reason the same way. So no equilibrium price exists. Under laissez faire the cab fare paid by each customer is the result of bargaining between him and the one taxi. A model that incorporates this feature is needed to dissect the laissez faire case. And here we encounter still further difficulties. As Cairns and Liston-Heyes (1996) observe, the Myerson-Satterthwaite (1983) theorem implies that bargaining between a cab driver and potential customer will not in general attain an efficient outcome if neither has an alternative trading partner at the moment (and so are uninformed regarding one another's valuations of trading). On this basis they suggest that regulation could therefore be beneficial in low demand periods. That may be, although one wonders how the regulators would become apprized of the same private information befuddling the traders themselves, even assuming they escape industry capture and so are able to act on the information in an efficient way. In any case this still leaves 
open the question on which I wish to focus, namely what is the precise character of the laissez faire regime.

The Myerson-Satterthwaite theorem of course presumes asymmetric information. If we drop that assumption-which timid souls may be unwilling to do-then it becomes possible to model the bargaining between cab driver and potential customer using the Rubenstein (1982) alternating offers setup. As I shall demonstrate below, this sort of approach accounts for the two-part pricing of taxi services under laissez faire. Furthermore it gives concreteness to comparisons of the taxi industry under laissez faire and under alternative regulatory regimes. The rationale and effects of regulation then become transparent. The nub of the matter is that the laissez faire regime as so construed (fares determined by Nash bargaining between each cab and customer) need not result in the efficient number of vacant cruising cabs. The number of vacant cabs could be either higher than optimal or less depending upon the relative bargaining power of individual cabs and potential customers. If the cab firms hold all of the bargaining power, as would be true under a cartel, or what amounts to the same thing a fully captured regulatory apparatus, then the number of vacant cabs and implied waiting time to hail a cab would be economically efficient.

For concreteness we focus on details of the Japanese regulatory regime but much of our analysis has applicability to taxicab regulation everywhere. We begin by describing the Japanese taxicab regulation and recent steps towards deregulation. Then we develop the model of taxicab pricing under laissez faire sketched above and use that model to speculate on the likely effects of taxicab regulation and deregulation. In particular, freeing entry while continuing to regulate fares, which Japan has effectively done as of February 2002 is likely to worsen allocation both compared to regimes in which fares and entry are both regulated (the status quo ex ante in Japan) and in comparison to complete laissez faire. 


\section{Taxicab regulations of Japan.}

The taxicab industry of Japan is subject to price and entry regulation by the national government (ministry of transport) under authority of the 1951 Road Transport Law. ${ }^{1}$ In this law, hire taxis (kashi kiri takushii) are distinguished from charter buses only insofar as buses carry 11 or more passengers and taxis 10 or fewer. Operation of a taxicab firm within any specified local region of Japan requires a license (menkyo) issued by the minister of transport. Article 6 of the Road Transport Law directs the minister of transport, in deciding whether to issue a license, to consider (among other things) whether entry of the applicant would cause the supply of taxi services to exceed the demand. ${ }^{2}$ This would seem to confer fairly sweeping authority to restrict entry, for if the regulated price is set high enough, any amount supplied will exceed the amount demanded. License applications specify the precise number of vehicles the firm intends to operate and any subsequent changes in that number whether increases or decreases require a new license. Licenses of individual taxi operators (that is sole proprietors, not the employees of taxicab firms) may only be issued to applicants over the age of 35 with previous experience as employees of licensed taxicab companies and who have passed examinations concerning both street directions and traffic laws.

According to the same Road Transport Law (article 9, section 2) cab fares are subject to prior approval (ninka) by the minister of transport. The law stipulates that such approval be

\footnotetext{
${ }^{1}$ On the basic facts regarding the Road Transport Law refer to Matsuzawa and Ishida (1995).

${ }^{2}$ The relevant passage included among the list of items to be considered in granting licenses to newly entering taxicab firms: "That entry of the firm in question would not, by virtue of its proposed service area or routes, cause the quantity of transport supplied to exceed the quantity demanded." ( tougai jigyou no kaishi ni yotte tougai rosen mata wa jigyou kuiki ni kakaru kyoukyuu yusou ryoku ga yusou juyou ryou ni taishi fukinkou to naranai mono de aru koto.) Road Transport Law, article 6. The other considerations pertain to the applicant's proper qualification to supply the proposed services.
} 
contingent on five considerations: (1) consistency with normal profit, (2) obeisance with the principle of nondiscrimination, (3) that the fare is not overly burdensome to passengers, (4) does not unfairly compete with the fares charged by trains or buses, and (5) lies within a range that is prescribed by the ministry. In 1955, responding to an outbreak of price competition among Tokyo cabs, the transport ministry adopted a principle that fares be the same for all cabs in the same size category operating within any given local area during the same hours. Fares were set slightly higher for large cabs than for mid-sized cabs or small cabs and set $30 \%$ higher after midnight, but within these categories were uniform within local regions.

In short, the Road Transport Law has vested the transport ministry of the national government with very broad powers to determine the number of taxicabs in each city and region of Japan and to also determine the fares. As part of a broad Japanese government mandate to deregulate, in June 1992 the transport ministry announced its intention within ten years to relax its implementation of this authority in two ways. It proposed to place less weight on the supply and demand considerations in bestowing licenses, and to reconfigure the fare structure to allow prices that are not strictly uniform within each geographic region. The first tangible manifestation of this new attitude towards the fare structure was the July 1993 introduction of a dual fare structure in the Osaka metropolitan region. 19,000 cabs were permitted to set initial fares of 600 yen, while 759 cabs were permitted to set the initial fare of 540 yen. The lower fare was applicable to the cabs of 6 companies and 3 individuals. In the following year 1994 a few individual taxicab operators in Osaka were allowed to refrain and did refrain from joining the great mass of cab firms and other individual operators in seeking to raise the permissible initial fare. The same year in Aomori prefecture two cab firms similarly refrained from joining rivals in seeking to raise their permissible initial fare. And in December 1993 three of the four Kyoto cab firms 
constituting the MK Group sought and obtained permission to actually lower their initial fares from 530 yen to 470 yen for small cabs and from 540 yen to 480 yen for mid-size cabs. ${ }^{3}$ The remaining member of the MK Group sought and obtained permission to raise its initial fare from 530 yen to 580 yen for small cabs and from 540 yen to 590 yen for mid-size cabs. At this same time all the other Kyoto cabs sought and obtained permission to raise initial fares from 590 yen to 630 yen for small cabs and from 600 yen to 640 yen for mid-size cabs. The end result was an unprecedented situation in which three different fare structures were permitted within the same geographic region. The four companies of the MK Group together operated 459 vehicles, about $5 \%$ of the Kyoto cab fleet.

Besides introducing a maverick fare structure, the MK Group sought two further unprecedented concessions. One was permission to run taxis along preset routes stopping only at city bus stops. ${ }^{4}$ This permission was denied. The other petition, which was allowed, treated MK cab drivers over the age of 60 and having 20 or more years of service as "individual operators" with their own licenses, even though they continued to operate MK cabs. In effect this allowed MK to expand its fleet (by six vehicles) without itself obtaining a new license. These recent changes fall far short of deregulation but have provoked a lot of discussion.

In March 2000 the cabinet submitted a bill to the Diet that it enacted in May of the same year to revise the Road Transport Law so that licenses to operate hire taxis or buses would be granted to any operators that meet safety standards. But the new law allows the transport ministry to

\footnotetext{
${ }^{3}$ On the facts regarding the MK group's maverick fares refer to: Iguchi Tomio, chiiki koutsuu to shite no takushii jigyou (the taxicab firm as regional transportation), ch. 8 in Iguchi Tomio, ed., kisei kanwa to chiiki keizai - Kyoto-shi to shuuhen chiiki no doukou (the regional economy and deregulation-- the trends in the city of Kyoto and its surrounding region), ryuukoku university social science research center monograph no. 25, zeimu keiri kyoukai, 1996.

${ }^{4}$ Klein, Moore and Reja (1997) argue that enforcement of exclusive ownership rights in preset routes actually improves resource allocation and that hire taxis should therefore be disallowed from following bus routes.
} 
exercise "emergency" measures to restrict entry into the taxi industry if the supply of taxis is deemed sufficiently excessive. A transport ministry official was quoted in the newspapers as asserting that excessive supply of taxis could cause "abusive competition" that might lead to a decline in cab safety. (The Japan Times, February 29, 2000). Also the new law leaves unchanged the system of regulating cab fares on the grounds that varying the fare system would, according to the bill itself, "confuse passengers". Such comments are of little help in understanding the true rationale for taxicab regulation. The worldwide ubiquity and persistence of taxicab regulation affords ample evidence that such a rationale indeed exists. In any case the new law has taken effect as of February 2002, essentially freeing entry while maintaining regulation of fares. To evaluate the situation we need an economic model, the building of which is our next task.

\section{Economic effects of taxicab regulation}

To evaluate the effects of regulation it is necessary to have a clear picture of the way an industry would operate in the absence of government control of entry and pricing. To that end, we here develop a simple model of pricing and entry in the taxicab industry under laissez faire. But we begin with some brief comments on the previous literature regarding taxicab economics.

Douglas (1972) and Mohring (1972) propose models of cruising taxi and bus company profits respectively under the assumption that fares are exogenously set equal to marginal cost. Both argue that under such a regime, at the economically efficient scale of operation, revenues would be insufficient to cover all costs which include the costs of operating vacant vehicles. It is necessary to operate vacant vehicles if transport services of a given quality are to be supplied because an increase in the number of vacant vehicles decreases the average waiting time and so 
is an economic good. But the costs of operating vacant vehicles arise as a fixed cost of supplying transport of a given quality and so would be unremunerated in a regime in which the fare is set equal to the marginal cost. Furthermore, a fare set higher than marginal cost would inefficiently discourage demand. Thus it would seem, as argued by Arnott (1996), that in addition to a fare set equal to marginal cost, a flat subsidy is needed to attain a first-best allocation. Beesley and Glaister (1983), Frankena and Pautler (1986), and Rometsch and Wolfstetter (1993) follow the same basic setup as Douglas. These authors all treat the fare as exogenously determined, presumably by regulatory fiat. Orr (1969) and DeVaney (1975) advance models which purport to characterize the laissez faire equilibrium, but do so by introducing the assumption that all cabs charge the same fare and its level depends in an ad hoc and deterministic way upon the parameters. In other words in their models as in the others already mentioned, the fare is in fact exogenously determined, according to a possibly sophisticated rule it is true, but not necessarily one that mimics the outcome of a completely laissez faire regime.

As discussed in the introduction, we need to model the bargaining between ndividual cabs and their customers to learn about the determination of fares under laissez faire. The excellent paper by Cairns and Liston-Heyes (1996) fully apprizes us of the analytic difficulties this entails. Specifically, if neither the cab driver nor potential customer know the other's value of trading, then in the logic of Myerson and Satterthwaite (1983) no individually rational and incentive compatible mechanism exists that assures trade will occur in the instances where it would be efficient (that is where the customer's valuation of a cab ride exceeds the cab driver's opportunity cost of providing it). The upshot is that it is difficult or impossible to fathom just exactly what the outcome of bargaining under asymmetric information might be. But surely the 
presumption of complete ignorance of the respective private valuations is a bit extreme. Some of the relevant influences on those values clearly are known by both parties such as the proposed length and duration of the trip. And perhaps the other influences on the private values do not vary so much among cab drivers and among potential customers respectively as to invalidate an economic model that presumes the values are in fact commonly known. While of course not disputing the analytic correctness of Cairns and Liston-Heyes' claims, I assert that a model of bargaining between cabs and customers based on an assumption of full information has potential empirical merit. The assumption that cab driver and potential customer each know the other's private valuations opens the way to apply the Rubenstein variant of the Nash bargaining model. This affords a very precise representation of the taxi industry under laissez faire that can be used as a standard for comparing alternative regulatory regimes. We begin with the case of identical demanders but at the end of the essay discuss some implications of relaxing that assumption.

\section{Basic framework}

We first set out some basic assumptions regarding demand and costs. Suppose that each demander's willingness to pay for a taxi ride is

(1) u-s $\theta$,

where $\theta$ is the expected waiting time and $u>0$ and $s>0$. Taxis cruise in a circle making one revolution per hour whether or not occupied. Demanders wait at an arbitrary spot on the circle and hail the first idle cab that passes. The expected waiting time for an idle cab (in hours) is thus the reciprocal of the number of idle cabs. 
There are $\mathrm{N}$ cabs with an average occupancy rate of $\tau$. The flow demand (normalized to equal the number of demanders in the market) is $y=\tau \mathrm{N}$. Accordingly, the expected waiting time to hail a cab is:

$$
\theta=1 /(\mathrm{N}-\mathrm{y})=1 /((1-\tau) \mathrm{N})=\tau /((1-\tau) \mathrm{y})
$$

Each demander's willingness to pay is thus

$$
\mathrm{v}(\mathrm{y}, \tau)=\mathrm{u}-\mathrm{s} \tau /((1-\tau) \mathrm{y})
$$

Let taxi costs be $\mathrm{C}=\mathrm{cN}=\mathrm{cy} / \tau$. If all customers are identical ( $\mathrm{s}$ and $\mathrm{v}$ do not vary over the population), then the social welfare function is

$$
\begin{aligned}
& \mathrm{W}={ }_{0} \int^{\mathrm{y}} \mathrm{v}(\mathrm{z}, \tau) \mathrm{dz}-\mathrm{cy} / \tau \\
& =\mathrm{yu}-\mathrm{s} \tau /(1-\tau)-\mathrm{cy} / \tau
\end{aligned}
$$

If there exists a number of cabs $\mathrm{N}>\overline{\mathrm{y}}$ (and an implied occupancy rate $\tau=\overline{\mathrm{y}} / \mathrm{N}$ ) such that $\mathrm{W}>0$, then the socially efficient allocation entails serving all the $\bar{y}$ demanders. In that case the socially efficient occupancy rate (and implied efficient number of cabs in the industry) are such that $\partial \mathrm{W} / \partial \tau=0:$

and $^{5}$

$$
\tau^{*}=/ \mathrm{N}^{*}=1 /\left(1+(\mathrm{s} /(\mathrm{c} \overline{\mathrm{y}}))^{1 / 2}\right)
$$

$\overline{{ }^{5} \mathrm{Write} W=\overline{\mathrm{yu}}-\mathrm{s} \overline{\mathrm{y}} /(\mathrm{N}-)-\mathrm{cN}}$ and find $\partial \mathrm{W} / \partial \mathrm{N}=\mathrm{s} \overline{\mathrm{y}} /\left(\mathrm{N}^{*-} \overline{\mathrm{y}}\right)^{2}-\mathrm{c}=0$ 


\section{Pricing under laissez faire}

Now consider the industry equilibrium in the absence of regulation. Each cab driver enters Nash bargaining over the fare with each individual customer that hails him; the agreed fare divides the gain from their trade with one another in a way that depends upon each's disvalue of prolonging bargaining (See the appendix). For a customer, the gain is the avoidance of waiting time (Cabs are identical and so all reach the same price bargain with any one customer). For the cab, the gain depends on the price paid, the discount rate and the duration of the ensuing trip. Agreement confers revenue immediately and upon conclusion of the trip leaves the cab in the same situation as before but for the passage of time. The value of agreement to the cab equals the fare minus the disvalue of postponing subsequent revenue for the duration of this trip. The longer the trip the smaller are the gains to the cab corresponding to any given fare. In the Nash bargaining, longer trips therefore command higher fares. For example the present value of cab revenue under the zero profit condition equals the present value of cost

$$
\int_{0}^{\infty} \mathrm{e}^{-\mathrm{rt}} \mathrm{cdt}=\mathrm{c} / \mathrm{r}
$$

where $\mathrm{c}$ is the cost of operating a cab (flow per time period $\mathrm{t}$ ) and $\mathrm{r}$ is the continuous discount rate per time period $\mathrm{t}$. Now the gain to the cab from a trip that has duration $\mathrm{x}$ and pays $\mathrm{p}$ is:

$$
\text { p- } 0_{0}{ }^{\mathrm{x}} \mathrm{e}^{-\mathrm{tt}} \mathrm{cdt}=\mathrm{p}-\left(1-\mathrm{e}^{-\mathrm{rx}}\right) \mathrm{c} / \mathrm{r}
$$

In the interior solution of the Nash bargain, the price $\mathrm{p}$ is determined so that the gains to the taxi relative to those of the customer depend upon the taxi firm's continuous discount rate $r$ and the customer's disvalue of prolonging bargaining (which we shall presume equal to the disvalue of waiting to hail a cab $=$ s per time unit) 


$$
\left(\mathrm{p}-\left(1-\mathrm{e}^{-\mathrm{rx}}\right) \mathrm{c} / \mathrm{r}\right) \div \mathrm{s} \theta=\mathrm{s} \div(\mathrm{r}-\mathrm{s})
$$

For a general statement of the Nash bargaining solution refer to the appendix. Nash bargaining between cab and customer as just described has some interesting implications. First, find that

$$
\mathrm{p}=\mathrm{s}^{2} \theta /(\mathrm{r}-\mathrm{s})+\left(1-\mathrm{e}^{-\mathrm{rx}}\right) \mathrm{c} / \mathrm{r}
$$

From this, we have that:

$$
\partial \mathrm{p} / \partial \mathrm{x}=c \mathrm{e}^{-\mathrm{rx}}>0
$$

Longer trips command a higher price. Furthermore

$$
\partial^{2} \mathrm{p} / \partial \mathrm{x}^{2}=-\mathrm{r} \partial \mathrm{p} / \partial \mathrm{x}
$$

This tariff structure might be approximated by a simple two-part (affine) tariff of the sort that is common in the taxi business.

Additionally,

$$
\partial \mathrm{p} / \partial \theta=\mathrm{s}^{2} /(\mathrm{r}-\mathrm{s})
$$

As new firms enter, shortening the average waiting time to hail a cab $(\theta=1 /(\mathrm{N}-\overline{\mathrm{y}}))$, the price will become lower if (r-s) is positive, which is the necessary and sufficient condition for the customers to realize any gain from trade at all. (In the contrary instance $r-s<0$, the Nash bargain 
confers the entire gain from trade on the taxi firm and $\mathrm{p}=\mathrm{u}-\mathrm{s} \theta$. So in this instance, too, $\partial \mathrm{p} / \partial \theta>0$. Entry of cabs lowers the price.)

The fare depends on the customer's disvalue of waiting s but not on his basic willingness to pay u. In other words customers may well vary in their basic willingness to pay u without altering the fare structure in any way. This suggests a way of slightly generalizing the model to allow differences among customers while still premising the fare on a presumption of bargining under complete information. For instance the basic willingess to pay u might vary over the population of customers and yet they still all have the identical known disvalue of waiting s...or perhaps s depends upon the distance of the proposed trip, those proposing shorter trips having a greater disvalue of waiting. I will not develop these more general models here but will later comment briefly on their implications.

In the present model, in the equilibrium under free entry, industry profit reaches zero:

$$
\pi=\mathrm{py}-\mathrm{cN}=0
$$

Again assuming that all customers are identical and that all customers are served (and that the Nash bargaining has an interior solution)

$$
\left.\pi=\mathrm{s}^{2} \overline{\mathrm{y}} /((\mathrm{r}-\mathrm{s})(\mathrm{N}-\overline{\mathrm{y}}))+\left(1-\mathrm{e}^{-\mathrm{rx}}\right) \overline{\mathrm{y}} \mathrm{c} / \mathrm{r}\right)-\mathrm{cN}
$$

and

$$
\partial \pi / \partial \mathrm{N}=-\mathrm{s}^{2} \overline{\mathrm{y}} /\left((\mathrm{r}-\mathrm{s})(\mathrm{N}-\overline{\mathrm{y}})^{2}\right)-\mathrm{c}<0 .
$$


As cabs enter, the number of vacant cabs increases and so the expected waiting time $(=1 /(\mathrm{N}-\overline{\mathrm{y}}))$ becomes shorter and the average price per cab trip correspondingly smaller. Industry revenue and profits decline as more cabs enter. The number of cabs that just attains zero profit $\mathrm{N}_{\mathrm{LF}}$ is (if greater than zero) ${ }^{6}$ :

$$
\left.N_{L F}=N \text { such that: } s^{2} \bar{y} /((r-s)(N-\bar{y}))+\left(1-e^{-r x}\right) \bar{y} c / r\right)-c N=0
$$

There are more cabs under laissez faire than is socially efficient if Nash bargaining greatly favors the taxi firms ( $\mathrm{s}$ is much greater than $\mathrm{Fs}$ ), and may be too few in the opposite case. The fundamental reason for this is that the price that results from bargaining may be either greater than the marginal social benefit of adding a new entrant or less, and which it is depends, in part, on whether the bargaining is slanted in favor of the taxis or their customers.

\section{Models of regulation}

As described in section 2 above, the Ministry of Transport of Japan (now known as the Ministry of Land Infrastructure and Transport) has, with only a few recent exceptions, insisted on uniformity of taxi fares within each geographic region. In effect this has meant that the cab firms coordinate their annual requests to revise the posted fare, all asking for virtually the identical revision. Consider therefore what fare would be set by the industry if acting in concert, given that the transport ministry limits entry to a maximum set number of cabs that does not

\footnotetext{
${ }^{6}$ It may well be that it is unprofitable to supply cab services at all $\left(\mathrm{N}_{\mathrm{LF}}=0\right)$ even though it is socially efficient to do so. In principle, a subsidy could be necessary to attain the social optimum.
} 
depend on the fare. In other words, the fare $\mathrm{p}$ is set to maximize industry profit given $\mathrm{N}$. In the identical demanders case the industry then sets the fare so as to fully appropriate the consumers' surplus. Industry profit becomes identically equal to social welfare. In this case the socially efficient rule in determining entry is to also maximize industry profit. If free-entry is allowed with collusive fares, there will be more cabs operating than is socially efficient. The Figure 1 indicates the basic logic. As drawn, $\mathrm{N}_{\mathrm{LF}}<\mathrm{N}^{*}$ (that is the number of cabs under free entry and laissez faire pricing is greater than is socially efficient), but as discussed above this is not necessarily always the case.

In the context of this simple example the prevalence of regulation of taxi markets the world over is readily explained. To precisely the extent that regulation establishes a perfect cartel, social welfare is enhanced (This is true whether under laissez faire there are too many cabs or too few). In Becker's (1983) theory of competition among pressure groups, special interest groups seeking to establish regulations that eliminate deadweight losses are more likely to succeed. The putative enhancement of social welfare has approximately the same effect as would a subsidy of political activity in support of the policy's adoption.

It is a simple matter to compare the social welfare, industry profit, consumer surplus and average price under each of the four regimes. With regard to the price (i.e. fare), first notice that under laissez faire pricing the average fare declines as there are more cabs and the average wait to hail a cab grows shorter. Under collusive pricing, as the average wait to hail a cab becomes shorter the willingness to pay rises and the fare is raised too to appropriate it. Thus the fare is lowest under complete laissez faire of both entry and pricing, next lowest under collusive entry conditions but laissez faire pricing, higher under a perfect cartel, and highest under collusive 
fares but free entry. Industry profit is greater under a perfect cartel than under collusive entry conditions and laissez faire pricing. Industry profit is equal to zero under free entry whether or not fares are set collusively. Consumer surplus is greater under complete laissez faire than under the other three regimes (in which it is equal to zero). Social welfare is greatest under a perfect cartel and lowest of all under collusive pricing with free entry. The ranking of social welfare under complete laissez faire and under laissez faire pricing but collusive entry conditions is ambiguous; it depends upon the relative bargaining positions of taxi firms and their customers.

Moving from a regime in which fares are set collusively but entry is free to one of complete laissez faire, will thus result in exit of firms, reduced fares, increased social welfare and increased consumer surplus. Moving from a regime in which fares are set collusively and entry is controlled to one of free entry (but still collusive fares) will lead to entry, increased fares, reduced profit, and reduced consumer surplus.

Finally, it is appropriate to question how these results might be altered under the generalizations of the model alluded to earlier that allow non-identical customers. Suppose that each customer has the same willingness to pay posited above $\mathrm{u}-\mathrm{s} \theta$, but that the parameter $\mathrm{u}$ varies in a known way over the population: $\mathfrak{u}(\underline{\mathrm{u}}, \overline{\mathrm{u}})$. Let us presume that each cab driver knows the value of $\mathrm{s}$ of each customer-either because it is the same for all customers or because it depends on other known facts such as the distance of the proposed trip. In this instance the fare is determined according to the same rule as before. Under laissez faire:

$$
p=s^{2} \theta /(r-s)+\left(1-e^{-r x}\right) c / r .
$$


But some customers that it would be economically efficient to serve given the actual number of idle cabs and implied waiting time $\theta$, may now not be served under laissez faire. These customers would be served only if, holding the number of idle cabs unchanged, the fare were lowered to match the marginal cost of the cabs, or

$$
\mathrm{p}=\left(1-\mathrm{e}^{-\mathrm{rx}}\right) \mathrm{c} / \mathrm{r} \text {. }
$$

In other words introducing the assumption of non-identical customers, so that the scale of the market demand varies inversely with the level of fares, brings to light an additional distortion of the laissez faire allocation. It is actually a monopoly distortion. Although there may be many independently competing taxi cabs, each has some bargaining power with respect to each of its customers, which confers a modicum of economic rent and a wedge between price and marginal cost.

What about cartels and regulation under the non-identical demanders model? Continue the assumption that each customer's basic willingness to pay u varies over the population but each's disvalue of waiting $s$ is identical (or at least known by the taxi firms). A taxi cartel would not be able to fully appropriate consumer surplus if it did not know each customer's full willingness to pay. It would however adjust the number of cabs so that the number of vacant cabs and implied waiting time of each customer was economically efficient, given the prices it set, which would lie above the laissez faire prices. In other words, the simple monopoly distortion would be greater under a cartel than under laissez faire, but the distortion of the number of vacant cabs would be less. Under collusive fares but free entry-one kind of regulatory regime-the monopoly distortion would remain but the number of vacant cabs would in fact be greater than the efficient 
one given the fare. Under regulation of both fares and entry a first-best outcome could in principal be achieved. This would entail marginal cost pricing combined with a subsidy to bring about the efficient number of vacant cabs, exactly as described by Arnott (1996).

\section{Conclusion.}

Taxicab industries the world over have been subject to regulation. To understand the rationale and implications requires a convincing model of how the industry would operate in the absence of regulation. This paper has proposed just such a model. Its essential feature is that under laissez faire, price is determined by Nash bargaining between each cab and its customer, with complete information. The agreed fare divides the gains from trade. For a customer, the gain is the avoidance of waiting for the next cab (Cabs are identical and so all reach the same price bargain with any one customer). For the cab, the gain equals the fare minus the disvalue of postponing subsequent revenue for the duration of this trip. Even if all customers are wholly identical to one another and all are served, the equilibrium under laissez faire pricing and freeentry will not in general entail the efficient number of vacant cabs and implied efficient waiting time to hail a cruising cab. This distortion is peculiar to the cruising taxi industry. A cartel would set higher fares than the laissez faire ones but would set the number of vacant cabs at the efficient level given the fares. If customers have the same known disvalue of waiting for the next cab but have varying willingnesses to pay for taxi services then the bargaining model developed here still applies to the laissez faire pricing regime, but the implied wedge between price and marginal cost then entails an additional distortion besides the distortion entailed in the divergence of number of vacant cabs from the efficient level. In other words, bargaining over 
fares between each cab and customer entails a degree of local monopoly. The rationale for taxi regulation now becomes apparent. First, even if regulatory capture entails collusive fare setting, its net distortions are made less than they otherwise would be by the fact that under laissez faire too pricing entails a degree of local monopoly. Second, even under regulatory capture, the number of vacant cabs would be set closer to the efficient evel, given the prices, than would be true under laissez faire pricing and free entry.

Japan is the latest country to experiment with deregulation of the taxi industry. From February 2002, entry into the industry has been largely freed of restrictions while fares remain subject to regulation. Based on the analysis of this paper it would be better to deregulate fares also if free entry is to be allowed, lest the number of vacant cabs rises far above the efficient level. In fact, freeing entry while continuing to regulate fares may actually be worse than continuing a regulatory regime that effectively entails both collusive fares and restricted entry. 
Appendix. The Rubenstein Bargaining Game ${ }^{7}$

Two persons must decide how to divide a dollar. The first proposes that he himself receive some specific share, $\alpha_{1}$ say. The second person, if he declines the original offer, proposes a counteroffer in which he himself should receive some specific share, $\alpha_{2}$ say. And so on, back and forth. Each round of offer and counteroffer requires time of length $t$. After each round, the two bargainers, $i=1,2$, incur costs of delay equal to st in the case of the first person (the "customer") and equal to the fraction 1- $\mathrm{e}^{-1 \mathrm{rt}}$ of the gross allocation in the case of the other (the taxi firm).

Now, the unique subgame perfect solution to this game is the pair $\left(\alpha_{1}, \alpha_{2}\right)$ representing the share each proposes to allocate to himself whenever it is his turn to make an offer, for the situation before each player is essentially unchanging whenever it is his turn to make an offer. The bargaining proceeds as follows:

$\begin{array}{lll} & \begin{array}{l}\text { Customer's } \\ \text { Allocation }\end{array} & \begin{array}{l}\text { Taxi Firm's } \\ \text { Allocation }\end{array} \\ \text { One } & \begin{array}{l}\text { Net of Costs } \\ \text { of Delay: }\end{array} & \begin{array}{l}\text { Net of Costs } \\ \text { of Delay: }\end{array} \\ \text { Proposing: } & \text { of Delay } & 1-\alpha_{1} \\ \text { Customer (1) } & \alpha_{1} & \alpha_{\mathbf{2}} \mathbf{e}^{-\mathbf{r t}} \\ \text { Taxi (2) } & 1-\alpha_{2}-\text { st } & \left(1-\alpha_{1}\right) \mathrm{e}^{-\mathrm{r} 2 \mathrm{t}}\end{array}$

....and so on, until an offer is accepted.

Consider the characteristics of $\alpha_{1}$ and $\alpha_{2}$. The taxi firm's initial counteroffer must be the least generous that it could expect the customer to accept:

$$
1-\alpha_{2}-\mathrm{st}=\alpha_{1}-2 \mathrm{st}
$$

In anticipation of such a counteroffer from the taxi, the customer's initial offer is the least generous it can expect the taxi to accept:

$$
1-\alpha_{1}=\alpha_{2} \mathrm{e}^{-\mathrm{tt}} \text {. }
$$

Solving these two equations, we find that

$$
\alpha_{1}=1-\mathrm{st} /\left(\mathrm{e}^{\mathrm{rt}}-1\right) \text {. }
$$

The customer proposes this allocation and the offer is immediately accepted by the taxi. The implication is that the share each obtains is larger, the greater is the opposite party's cost of prolonging bargaining. Furthermore, the first to propose an offer (in the example here, the customer) holds an advantage. In the limit, as the successive rounds are presumed to transpire more rapidly, the "first-mover" advantage dissipates, but the respective costs of prolonging bargaining still influence the outcome:

$$
\lim _{\mathrm{t} \rightarrow 0} \alpha_{1}=1-\mathrm{s} / \mathrm{r} \text {, and } \alpha_{2}=1-\alpha_{1}=\mathrm{s} / \mathrm{r} \text {. }
$$

Notice that for there to be an interior solution (our implicit assumption above)it must be that $\mathrm{s}<\mathrm{r}$. If $s>r$ the solution becomes $\alpha_{2}=1$; the entire gains from trade go to the taxi.

\footnotetext{
${ }^{7}$ Based on: Ariel Rubenstein. "Perfect Equilibrium in a Bargaining Model”, Econometrica, vol. 50, no. 1, 1982, pp. 97-109.
} 


\section{References}

Arnott, Richard (1996). "Taxi Travel Should Be Subsidized", Journal of Urban Economics, vol. 40, pp. 316-33.

Becker, Gary (1983). “A Theory of Competition Among Pressure Groups”, Quarterly Journal of Economics, vol 98, pp. 371-400.

Beesley, Michael E. and S. Glaister (1983). "Information for Regulating: The Case of Taxis", Economic Journal, vol. 93, no. 371 (Sept.) pp. 594-615.

Cairns, Robert D. and Catherine Liston-Heyes (1996). "Competition and Regulation in the Taxi Industry”, Journal of Public Economics, vol. 59, pp. 1-15.

DeVaney, Arthur S. (1975). "Capacity Utilization under Alternative Regulatory Restraints: An Analysis of Taxi Markets", Journal of Political Economy, vol. 83, no. 1 (Feb.), pp. 83-94.

Douglas, George W. (1972). "Price Regulation and Optimal Service Standards: The Taxicab Industry", Journal of Transport Economics and Policy, vol. 4, no. 2 (May), pp. 116-127.

Frankena, Mark W. and Paul A. Pautler (1986). “Taxicab Regulation: An Economic Analysis", Research in Law and Economics, vol. 9, pp. 129-165.

Iguchi Tomio. chiiki koutsuu to shite no takushii jigyou (the taxicab firm as regional transportation), ch. 8 in Iguchi Tomio, ed., kisei kanwa to chiiki keizai - Kyoto-shi to shuuhen chiiki no doukou (the regional economy and deregulation-- the trends in the city of Kyoto and its surrounding region), ryuukoku university social science research center monograph no. 25, zeimu keiri kyoukai, 1996.

Klein, Daniel B. , Adrian Moore and Binyam Reja (1997) Curb Rights: A Foundation for Free Enterprise in Urban Transit, Washington DC: Brookings Institution Press.

keizai kikakuchou sougou keikaku kyoku (economic planning agency of the Japanese government, universal planning bureau). kisei kanwa no keizai riron (economic theories of deregulation), Government of Japan, 1989.

Matsuzawa Toshio and Ishida Nobuhiro. douro ryokaku yusou (road passenger transport), ch.5 in Kanemoto Yoshitsugu and Yamauchi Hirotaka, eds., kouza: kouteki kisei to sangyou, yon-satsu: koutsuu (seminar: industry and public regulation, vol.4: transport), NTT publishing company, 1995, pp. 193-232.

Mohring, Herbert (1972). "Optimization and Scale Economies in Urban Bus Transportation”, The American Economic Review, vol. 62, no. 4 (Sept.), pp. 591-604.

Myerson, Roger B. and Satterthwaite, Mark A. (1983). "Efficient Mechanisms for Bilateral Trading”, Journal of Economic Theory, vol. 29 (April), pp. 265-281. 
Orr, Daniel (1969). “The 'Taxicab Problem': A Proposed Solution”, Journal of Political Economy, vol. 77, no. 1 (Jan/Feb), pp. 141-7.

Rometsch, Stefan and Elmar Wolfstetter (1993). "The Taxicab Market: An Elementary Model", Journal of Institutional and Theoretical Economics, vol. 149, no. 3, pp. 531-546.

Rubenstein, Ariel (1982). "Perfect Equilibrium in a Bargaining Model”, Econometrica, vol. 50, no. 1, pp. 97-109.

Stiglitz,Joseph E. (1989). "Imperfect Information in the Product Market", in R. Schmalensee and R.Willig, eds., Handbook of Industrial Organization, vol. 1, North-Holland, Amsterdam, pp. 769-847.

takushii unchin seido kenkyuukai koukokusho (research center report on the taxi fare system). ch. 5 in: unyushou unyu seisaku kyoku, unyu keizai kenkyuu sentaa (ministry of transport of the government of Japan, transport policy bureau, center for research on transport economics) kore kara no ryokaku unchin --atarashii ryokaku unchin no seittei houshiki (passenger fares in the future--the new method of setting passenger fares) April 8, 1996. 
Figure 1. Industry profit under market pricing $\pi$, and social welfare $\mathrm{W}$ (=industry profit under collusive fare-setting) in alternative regimes.

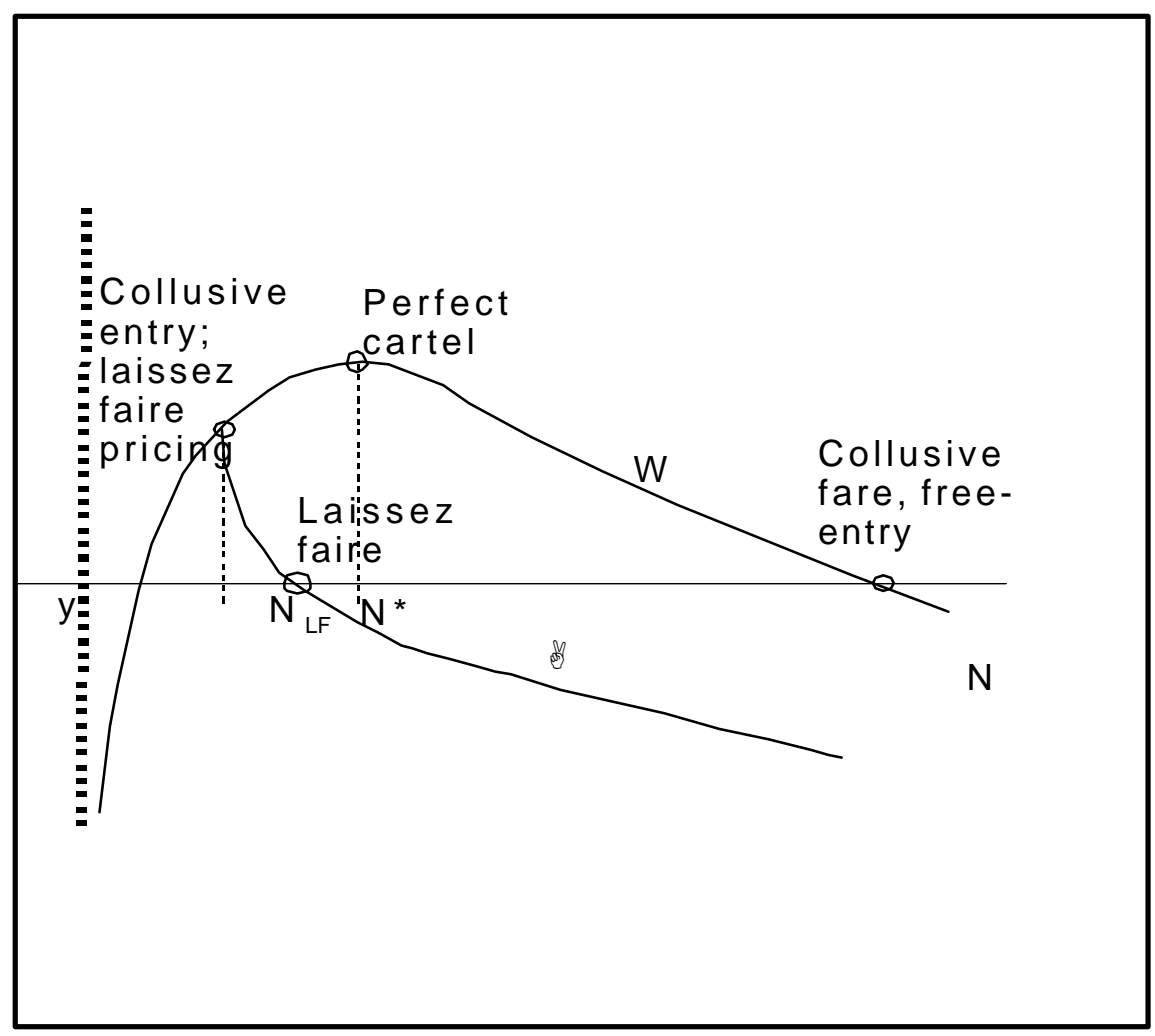

